19- Tempo

\title{
São Paulo na virada do século $X X$ : um laboratório de saúde pública para o Brasil $^{*}$
}

\author{
Marta deAlmeida**
}

E ste artigo diagnostica o quadro tenso da institucionalização da microbiologia no Serviço Sanitário de São Paulo, fundado em 1891, e o seu papel na história da saúde pública do país. D iscute a necessidade de articulação dos expoentes médicos daquele E stado com outros centros científicos e sanitários, tanto no país quanto no exterior, enquanto necessária estratégia de consolidação profissional e social, e destaca o papel das iniciativas sanitárias de São Paulo no cenário nacional.

Palavras-chave: $\mathrm{H}$ istória-Saúde Pública-São Paulo.

São Paulo at the turn of the20th century: a public health laboratory for B razil $T$ his article examines the complex frame of the institutionalization of microbiology in the Sanitary Service of São Paulo, an organization created in 1891, and the role this Service has played in the history of public health in B razil. An articulation between its medical leaders and the state and other scientific and public heal th services, both in the country and abroad, was required as an essential strategy for the consolidation of their professions and the field of public health.

Key words: $\mathrm{H}$ istory - Public H ealth - São Paulo.

\footnotetext{
* Artigo recebido em fevereiro de 2005 e aprovado para publicação em abril de 2005.

${ }^{* *}$ Pesquisadora do M useu de Astronomia e Ciências Afins/M AST . E -mail: marta@mast.br Tempo, Rio de Janeiro, no 19, pp. 77-89
} 
São Paulo au début du XX è siècle: un laboratoire de santé publique pour le B résil

Cet article presente le cadre empreint de tension de l'institutionnalisation de la microbiologie dans le Service sanitaire de São Paulo (1891) et son rôle dans I'histoire de la santé publique au pays. II examine le besoin de rapprochement des autorités médicales de cet état avec d'autres centres scientifiques et sanitaires, soit du pays ou de l'extérieur, comme stratégie nécessaire pour sa consolidation professionnelle et sociale.

M ots-clefs: H istoire - Santé Publique - São Paulo.

\section{Introdução}

As novas possibilidades de intervenção médico-sanitária nos espaços públicos e privados, a partir dos princípios da microbiologia, no final do século XIX, causaram reações pouco receptivas, tanto na E uropa como no Brasil. E $m$ São Paulo, num período de crescimento frenético da cidade e também das epidemias - febre amarela, varíola, cólera, entre outras - foi criado o Instituto Bacteriológico (1892), por ordem da direção do Serviço Sanitário do E stado, fundado um ano antes ${ }^{1}$.

E ntre o final do século XIX e os primórdios do XX, paral elamente ao seu crescimento de maior produtor mundial de café, São Paulo via surgir também diversas instituições científicas, muitas delas vinculadas diretamente às atividades sanitárias. A relação destas duas dimensões da vida paulista, quais sejam, a dinâmica econômica e a política sanitária, tornou-se tema privilegiado de alguns trabal hos nas décadas de 80 e 90 do século passado. Segundo estas interpretações, a Primeira R epública seria o marco fundamen-

\footnotetext{
${ }^{1}$ O Serviço Sanitário foi o órgão governamental responsável pelas questões de saúde pública de São Paulo durante 47 anos e substituiu a Inspetoria de H igiene da Província. E ra um órgão subordinado à Secretaria do I nterior e responsável pela orientação do governo acerca dos assuntos de higiene e salubridade pública, pela aplicação de planos e pela execução do regulamento sanitário. Além do I nstituto B acteriológico, era formado pelo I nstituto Vacinogênico, pelo $\mathrm{H}$ ospital de I solamento, pelo L aboratório de Análises Q uímicas, pelo D esinfectório G eral e pelo I nstituto Butantan, criado posteriormente. C f. R odolfo M ascarenhas, " $\mathrm{H}$ istórico administrativo dos serviços estaduais de saúde pública de São Paulo", São Paulo, T ese de D outorado, U niversidade de São Paulo, F aculdade de Saúde Pública, 1949.
} 
São Paulo na virada do século XX: um laboratório de saúde pública para o B rasil

tal para compreender a ação institucionalizada por parte das autoridades públicas com relação às questões sanitárias².

N o final da década de 1990, pesquisas realizadas a respeito da história da medicina e da saúde pública em São Paulo privilegiaram outros temas através de estudos de caso, explorando fontes inéditas e com uma articulação teórica com proposições mais recentes de análise em história das ciências. A preocupação maior deixou de ser a elaboração de sínteses e modelos explicativos sobre saúde pública em São Paulo, para explorar aspectos pouco ou não estudados, problematizando a produção de conhecimento e as práticas médico-sanitárias implementadas naquele momento ${ }^{3}$.

A inserção da microbiologia em São Paulo: idéa eações para além das fronteiras regionais

A microbiologia, ciência que busca especificamente estudar a formação, o desenvolvimento e as funções dos seres microscópicos, ao contrário do que se afirma convencionalmente, não derivou instantaneamente das "descobertas de Pasteur", mas se consolidou aos poucos na história da medicina, através de diversos procedimentos, como a identificação e o isolamento de microorganismos patogênicos e a manipulação, chegando aos métodos preventivos de vacinas e à abertura terapêutica com a soroterapia,

\footnotetext{
${ }^{2}$ E merson E lias M erhy, 0 capitalismo e a saúde pública: a emergência das práticas sanitárias no E stado deSão Paulo, Campinas/São Paulo, Papirus, 1987; J ohn A. B lount, "T he Public H ealth M ovement in São Paulo, B razil: A H istory of the Sanitary Service, 1892-1918", Tese de Ph.D ., Tulane U niversity, 1971; L uiz Antonio de C astro Santos, "Power, I deology and Public H ealth in Brazil, 1889-1930", T ese de D outorado, C ambridge, M ass., H arvard U niversity, 1987 e, do mesmo autor, "A R eforma Sanitária 'Pelo Alto': O Pioneirismo Paulista no I nício do Século XX", DAD OS - Revista deCiências Sociais, vol. 36, no3, Rio de J aneiro, 1993, pp. 361-391; M aria Alice R osa R ibeiro, H istória sem fim...I nventário da saúde pública. São Paulo -1880-1930, São Paulo, E ditora da U nesp, 1993; M assako I yda, Cem anos deSaúdePública. A cidadania negada, São Paulo, E ditora da Unesp, 1994; R odolfo T elarolli Junior, Poder e saúde: as epidemias e a for mação dos ser viços de saúde em São Paulo, São Paulo, E ditora da U nesp, 1996.

${ }^{3}$ E ntre outros, L uiz Antonio Teixeira, "A Sociedade de M edicina e Cirurgia de São Paulo, 1895-1913", São Paulo, Tese de D outorado, U niversidade de São Paulo, F aculdade de F ilosofia, L etras e C iências H umanas, 2001; M árcia R egina B arros da Silva, "O mundo transformado em laboratório: ensino médico e produção de conhecimento em São Paulo de 1890 a 1933", São Paulo, T ese de D outorado, U niversidade de São Paulo, F aculdade de F ilosofia, L etras e Ciências H umanas, 2004; M arta de Almeida, R epública dos I nvisíve's: E mílio R ibas, mi crobiologia esaúdepública em São P aulo (1898-1917), Bragança Paulista, E ditora da U niversidade São F rancisco, 2003.
} 
entre 1890 e $1894^{4}$. N os últimos vinte anos do século XIX, em várias partes do mundo, conformou-se um novo estilo médico, num ambiente de práticas consolidadas no campo da cirurgia e da higiene.

Os matizes locais e a situação específica de cada região ou país devem ser levados em conta, para compreendermos a institucional ização da microbiologia, não enquanto uma etapa da evolução da medicina, homogênea e universal, mas enquanto um processo constantemente transformado, na medida em que adentrou diferentes realidades culturais.

Com base nesta perspectiva é que identificamos o processo de introdução da microbiologia no Brasil, no qual São Paulo teve papel fundamental. $\mathrm{N}$ a verdade, o final do século XIX já estava marcado pela forte presença dos princípios microbiológicos na medicina. Segundo B enchimol, em 1890 a microbiologia apresentava característica estrutural importante. $\mathrm{H}$ avia grande publicação de manuais, com vasto repertório de cânones e regras, o que não excluía, é claro, o movimento dinâmico da transformação e da inovação daquela área de conhecimento, movimento do qual os cientistas e os médicos que atuaram no Brasil fizeram parte ${ }^{5}$. A criação do Instituto Bacteriológico de São Paulo insere-se nesta dinâmica. F azia parte das primeiras seções auxiliares do Serviço Sanitário, juntamente com o laboratório de análises químicas (responsável pela análise de alimentos, águas minerais, bebidas, remédios) e com as repartições que já pertenciam, de alguma forma, à antiga I nspetoria de $\mathrm{H}$ igiene.

R eforçando a convicção de que o diretor daquela instituição deveria ser alguém altamente capacitado e integrado às inovações bacteriológicas, as autoridades paulistas buscaram inicialmente uma indicação da F rança. F oi nomeado o cientista F élix L e D antec, indicado pelo próprio Pasteur para ocupar o cargo, que previa não só a realização de atividades científicas laboratoriais como também cursos para formação de especialistas ${ }^{6}$. Sua rápida permanência no Brasil como diretor do I nstituto Bacteriológico, de dezembro de 1892 a abril de 1893, gerou protestos por parte de determinadas auto-

\footnotetext{
${ }^{4}$ C laire Salomon-Bayet, Pasteur et la Révolution Pasteurienne, Paris, Payot, 1986, p. 18.

${ }^{5} \mathrm{~J}$ aime Benchimol, D os mi cróbios aos mosquitos: febreamarela ea revolução pasteuriana no B rasil, Rio de Janeiro, F iocruz, Ed. UF RJ, 1999, p. 300.

${ }^{6} \mathrm{~F}$ ernando CerqueiraL emos, "C ontribuição à história do I nstituto Bacteriológico (1892-1940)", R evista do I nstituto Adol fo L utz, laboratório desaúdepública, São Paulo, vol. 14, 1954, p. 17.
} 
São Paulo na virada do século XX: um laboratório de saúde pública para o B rasil

ridades médicas e políticas, que 0 acusaram de apenas fazer algumas coletas e preparações sobre a febre amarela, levando-as para a E uropa, sem prestar qualquer outro serviço. F oi substituído, então, por $A$ dolfo $L$ utz ${ }^{7}$, subdiretor do Instituto desde março de 1893, que assumiu interinamente a direção até efetivar-se, em 1895, ficando no cargo até 1908, quando se transferiu para $M$ anguinhos.

E ste período foi marcado por uma série de polêmicas quanto aos diagnósticos emitid os pelo I nstituto, mas também pode ser considerado o período de sua consolidação no meio médico-científico do Brasil. As novas concepções microbiológicas com relação às doenças infecciosas sofriam oposição de grande parte dos médicos, das autoridades e da população. Os diagnósticos emitidos pelo I nstituto eram freqüentemente contestados por expressivo número de médicos que atuavam em São Paulo, desconfiados das análises laboratoriais que, muitas vezes, contrariaram seus laudos clínicos. Tal situação não ocorreu somente no Brasil, mas também nos países europeus. As ações voltadas para a implantação do paradigma bacteriológico e a conformação de um sentido novo ao espaço do laboratório na medicina foram resultado de um longo processo de confrontações e negociações.

\section{São Paulo deolhos abertos para ver eser visto}

Passamos a destacar alguns exemplos de articulação que o Serviço Sanitário de São Paulo realizou entre os trabal hos laboratoriais e as práticas consagradas da "boa higiene pública", principalmente durante a direção de E mílio M arcondes Ribas ${ }^{8}$, que considerou vários médicos da repartição entre eles o diretor do Instituto Bacteriológico, Adolfo L utz, o diretor do Instituto Vacinogênico, Arnaldo Vieira de Carvalho, o diretor da R evista

\footnotetext{
${ }^{7} \mathrm{~N}$ asceu no Rio de J aneiro em 1855, estudou na Suíça e freqüentou os laboratórios da F rança, da Alemanha e da Inglaterra. D irigiu o H ospital Kalihi no H avaí, a fim de investigar a lepra. D esenvolveu diversas pesquisas em São Paulo e no R io de J aneiro, destacando-se na área de entomologia no I nstituto O swald o C ruz até o ano de sua morte, em 1940, apud C arlos da Silva L acaz, Culto ao passado, São Paulo, F aculdade de M edicina da U SP, s/d.

${ }^{8}$ E mílio R ibas, nascido na cidade de P indamonhagaba, interior de São Paulo e médico formado pela F aculdade de M edicina do R io de Janeiro, chefiou o Serviço Sanitário entre 1898 e 1917. D urante estes anos, dirigiu com pulso forte a repartição e desenvolveu diversos trabaIhos sobre variad os temas, como febre amarela, varíola, tuberculose, lepra, entre outros, muito incentivado pelos desafios enfrentados durante sua gestão. Cf. M arta de Almeida, R epública dosInvisíveis..., op. cit.
} 
M édica de São Paulo, Victor G odinho, e o diretor do I nstituto B utantan, Vital B razil - verdadeiros aliados em seu plano-piloto de administração.

E mílio Ribas via na aliança entre microbiologia e higiene o verdadeiro alicerce para implementação de uma política sanitária efetiva não só para São Paulo como também para o B rasil ${ }^{9}$. Para ele, assim como para os demais membros do Serviço Sanitário, era fundamental ganhar a batalha contra toda espécie de oposição, desde as advindas das forças populares até as originadas no próprio meio médico, uma vez que não havia consenso, mesmo entre os que advogavam os cânones da microbiologia. $\mathrm{N}$ ão nos pareceu tarefa fácil.

Aqui, retomamos as colocações, em voga na literatura, de que a ausência de uma tradição de educação médica em São Paulo, até o início do século XX, seria facilitadora para as novas teorias sobre a causa de doenças ${ }^{10}$. Sugerimos que o fato de terem ocorrido entraves para implementação de uma faculdade de medicina em São Paulo $0^{11}$ não deve significar ausência de projetos e de uma mentalidade científica entre profissionais médicos atuantes no E stado, já na segunda metade do século XIX, preocupados com a importância do ensino médico e atentos às inovações.

J unto ao Serviço Sanitário, havia o associativismo profissional, as revistas médicas, os laboratórios particulares, as clínicas, enfim, um conjunto plural que formava um ambiente capaz de representar espaços também de aprendizagem do ofício médico, independente da existência de uma instituição concreta com o nome de faculdade de medicina ${ }^{12}$.

M uitos profissionais vislumbraram a criação da faculdade e propuseram, em instituições diversas, atividades ligadas ao ensino médico, como as ocorridas no Instituto Pasteur de São Paulo, fundado em 1903, na F aculdade de F armácia, fundada em 1900, na R evista M édica de São Paulo, fundada em 1898, e na Sociedade de M edicina e Cirurgia de São Paulo, fundada em $1895^{13}$. E stas iniciativas estavam inseridas no campo médico paulista,

\footnotetext{
${ }^{9}$ É de sua autoria a seguinte frase: “E ntre as múltiplas ciências subsidiárias da higiene nenhuma ocupa, sem dúvida, papel mais importante do que a microbiologia." E mílio Ribas, Curso de Bacteriologia (proposta), R evista M édica deSão Paulo, ano 7, no 16, 1905, p. 358.

${ }^{10} \mathrm{Cf}$. C astro Santos, "Power, I deology...", op cit.

${ }^{11}$ E mbora houvesse na legislação estadual de São Paulo, desde 1891, a previsão da criação de uma faculdade de medicina, o curso só foi oficializado em dezembro de 1912.

${ }^{12}$ M árcia R egina Barros da Silva, “O mundo transformado em laboratório...", op. cit., p. 137.

${ }^{13}$ L uiz Antonio Teixeira, "A Sociedade de M edicina e Cirurgia..." , op. cit.
} 
formado por instituições mais antigas. A existência e a atuação de instituições como a Santa Casa de M isericórdia, o Instituto Vacínico, transformado em 1893 em Instituto Vacinogênico, o H ospital de I solamento e mesmo a antiga estrutura sanitária do período imperial - a Inspetoria G eral de H igiene, criada em 1886, mesmo funcionando em condições precárias - demonstram haver uma organização considerável da categoria médica em São Paulo e uma diversidade de espaços para suas práticas, com inovações experimentais tanto na dimensão clínica como na dimensão laboratorial.

O utro aspecto que devemos levar em conta refere-se ao fato de que muitos dos médicos atuantes no início do século XX se formaram na $F$ aculdade de $M$ edicina do $\mathrm{R}$ io de $\mathrm{J}$ aneiro e, em menor número, na $\mathrm{F}$ aculdade de $M$ edicina da Bahia. Afirmar que as faculdades de medicina no B rasil representaram um obstáculo ao progresso científico no início do século passado também pode limitar a percepção de que havia um movimento dinâmico das idéias que circulavam nos corredores e nas salas de aula, seja enquanto projeto político de reforma educacional, seja enquanto reivindicação de al guns professores e jovens estudantes de medicina.

I mporta aqui ressaltarmos a formação de uma nova mental idade, consolidando-se enquanto estilo médico considerado moderno ${ }^{14}$. E eram justamente os estudantes que, depois de formados, retornavam para São Paulo, muitos deles com sonhos e projetos inovadores para o papel do médico na sociedade. E ncaixam-se neste perfil, além do próprio E mílio Ribas, Sérgio M eira, Victor Godinho, Artur M endonça, Vital Brazil, Arnaldo Vieira de Carvalho, Rubião M eira e tantos outros, que colaboraram no processo de profissionalização e atuação médicas em São Paulo.

Conforme dissemos, para esta nova mentalidade, pautada nos modelos de propagação das doenças por microorganismos, as "provas" de especificidade etiológica, vindas do processo de criação experimental da doença, as ilações entre a existência de vetores e 0 aparecimento de doenças eram alvo de intensas controvérsias médicas ${ }^{15}$. As publicações foram utilizadas

${ }^{14} \mathrm{Cf}$. F lávio Coelho E dler, "O debate em torno da medicina experimental no Segundo Reinado", H istória, Ciências, Saúde - M anguinhos, vol. 3, no 2, 1996, pp. 284-299, e, do mesmo autor, "As reformas do ensino médico e a profissionalização da medicina na Corte do Rio de J aneiro, 1854-1884" , São Paulo, D issertação de M estrado, U niversidade de São Paulo, F aculdade de Filosofia, L etras e Ciências H umanas, 1992.

${ }^{15} \mathrm{~L}$ uiz Antonio Teixeira, "A Sociedade de M edicina e Cirurgia...", op. cit. 
neste período enquanto importante estratégia para a difusão das novas pesquisas e procedimentos adotados no Serviço Sanitário, tanto as de caráter mais científico, em revistas especial izadas ou no formato de livros e manuais, quanto as de caráter de divulgação das ciências, principalmente em jornais.

U m exemplo a ser considerado é a própria produção científica de Adolpho L utz. N o comando do Instituto Bacteriológico, manteve regularidade de publicação de praticamente todas as pesquisas realizadas nas dependências laboratoriais do I nstituto ${ }^{16}$. O utros membros do Serviço Sanitário publicaram uma diversidade de trabal hos desenvolvidos em suas repartições, com o apoio oficial do E stado de São Paulo, como livros e monografias. T ambém era comum o fato de enviarem resultados de pesquisa e relatórios de atuação sanitária para as revistas médicas.

O utra forma de divulgação dos trabalhos realizados nas dependências do Serviço Sanitário a ser considerada refere-se aos congressos médicos nacionais e internacionais ${ }^{17}$. Adolfo L utz, E mílio R ibas, Victor G odinho, Vital B razil e tantos outros médicos, atuantes em São Paulo, tiveram participação efetiva nestes eventos. E $m$ 1903, por ocasião do $5^{\circ}$ Congresso Brasileiro de M edicina e Cirurgia, ocorrido no Rio de J aneiro, vários médicos de São Paulo marcaram presença. M uitos trabal hos apresentados voltaram-se para a febre amarela e a própria programação previu três temas gerais relacionados a ela. $\mathrm{N}$ o Brasil, os trabalhos mais ousados a respeito desta doença foram desenvolvidos pelos médicos de São Paulo. A pós a publicação de um franco manifesto de apoio à teoria que defendia ser um tipo de mosquito o responsável pela transmissão da febre amarela, o então diretor do Serviço Sanitário do E stado, E mílio R ibas, iniciou, em 1902, preparativos para refazer, aqui no Brasil, as polêmicas experiências ocorridas em H avana, em 1901, sobre a transmissão da febre amarela por mosquitos. E las ocorreram no H ospital de I solamento de São Paulo, sendo utilizados "voluntários" - inclusive R ibas e L utz - para comprovar a transmissão da doença por mosquitos e o seu caráter não contagioso.

\footnotetext{
${ }^{16}$ Para a bibliografia de L utz, consultar Jaime L arry Benchimol, M agali R omero Sá, J ohann Becker et alii, "A dolpho L utz e a história da medicina tropical no B rasil, T rabal hos Científicos de Adolpho L utz, publicados ou inéditos" , H istória, Ciências, Saúde- M anguinhos, Rio de Janeiro, vol. 10, no 1, 2003, pp. 287-409.

${ }^{17} \mathrm{M}$ arta de Almeida, "D a Cordilheira dos Andes à I sla de Cuba, passando pelo Brasil: os congressos médicos latino-americanos e brasileiros (1888-1929)" , T ese de D outoramento, São Paulo, U niversidade de São Paulo, F aculdade de F ilosofia, L etras e C iências H umanas, 2004.
} 
Além da publicação e da divulgação do relatório oficial de São Paulo, os trabal hos realizados foram relatados no $5^{\circ}$ Congresso, na seção de medicina geral. E mbora tais trabalhos fossem de autoria de E mílio R ibas, o mesmo não esteve presente no congresso, mas acompanhou atentamente o desenrolar das discussões, através de correspondências com os seus representantes. M uito provavelmente, quisera proteger-se dos ataques agudos que se faziam por todos os lados, vindos de São Paulo, da capital federal ou de outras regiões. $\mathrm{N}$ os documentos referentes às sessões preparatórias, evidencia-se que não havia qual quer previsão sobre o impacto que estes trabal hos apresentados teriam no evento.

D iante dos intensos debates ocorridos no Congresso, o plenário aprovou, em sessão especial, uma proposta para nova leitura das conclusões de $R$ ibas. Às duras penas, votou-se favoravelmente pela validade das suas conclusões, com o adendo de que nenhum outro modo de transmissão da febre amarela estava demonstrado rigorosamente, o que desagradou aos "exclusivistas" - os que acreditavam que havia somente o mosquito como forma de transmissão.

Além dos trabal hos inscritos sobre a febre amarela, houve grande destaque para uma outra série de trabal hos, desenvolvida pelos médicos de São Paulo, Vital B razil e Vitor G odinho, a respeito da soroterapia da peste bubônica e do ofidismo, temas centrais desenvolvidos no I nstituto Butantan ${ }^{18}$. A repercussão dos trabal hos apresentados pelos paulistas foi tão grande que a cidade de São Paulo foi aclamada por unanimidade para sediar o próximo congresso que, de fato, ocorreu em terras paulistas, em 1907.

D estaca-se o "sucesso" de um encontro ocorrido em uma cidade de poucos atrativos turísticos e com uma pequena rede hoteleira, enquanto resultado do empenho da comissão organizadora ${ }^{19}$ paulista, que promoveu 0 maior evento médico de caráter nacional até então. H ouve mais de 400 inscrições e, seguramente, a participação de, no mínimo, 220 congressistas. F oi o maior congresso médico nacional em termos de participação.

\footnotetext{
${ }^{18}$ Victor G odinho, Soroterapia da peste. Valor curativo do soro antipestoso do B utantan, e Vital Brazil, Da soroterapia no envenenamento ofídico. M emórias - Quinto Congresso Brasileiro de M edicina e Cirurgia, Rio de Janeiro, vol. 2, 1904, pp. 19-36 e 143-169.

${ }^{19} \mathrm{~A}$ comissão organizadora era formada por membros do Serviço Sanitário: E mílio R ibas (presidente), Vital Brazil (tesoureiro) e Victor G odinho (secretário).
} 
H avia repercussão dos trabal hos efetuados pelo Serviço Sanitário de São Paulo em outras partes do B rasil. M uitas doses de vacinas e soros produzidos no Instituto Vacinogênico e no Instituto Butantan eram enviadas para Campos (RJ ), Paraná, Bahia, M aranhão, R io Grande do Sul e até mesmo para outros países, como Inglaterra, Í ndia, F rança e E quador ${ }^{20}$.

$\mathrm{N}$ as exposições de higiene, ocorridas por ocasião dos congressos médicos do Brasil e do exterior, estes institutos e outras repartições do Serviço Sanitário participaram ativamente e foram premiados com medalhas. $\mathrm{N} \mathrm{a}$ E xposição Internacional de H igiene, realizada em 1907, em M ontevidéu, 0 B rasil foi representado somente por instituições paulistas, quase todas ligadas ao Serviço Sanitário. T anto o I nstituto Vacinogênico de São Paulo, quanto o H ospital de I solamento, o I nstituto Soroterápico Butantan e o D esinfectório levaram diversas fotografias dos respectivos edifícios e de suas dependências. 0 Butantan também levou mostras de soro antiofídico. A Associação Paulista dos Sanatórios para Tuberculosos, além de fotos, apresentou diagramas e quadros estatísticos ${ }^{21}$. N a E xposição de 1909, no R io de Janeiro, sede do $4^{\circ} \mathrm{C}$ ongresso M édico L atino-Americano, o E stado de São Paulo foi representado pelas principais instituições que formavam o Serviço Sanitário do E stado, além do Instituto Pasteur, grupos escolares, repartição de águas e esgotos, serviço de identificação e M aternidade de São Paulo.

O aparato médico paulista aos poucos transformava-se num símbolo de eficiência sanitária para o país. E m 1904, devido aos surtos epidêmicos de peste bubônica no M aranhão, o Serviço Sanitário foi contatado pelas autoridades governamentais daquele $\mathrm{E}$ stado para dirigir os trabal hos de combate à doença, para o qual E mílio R ibas comissionou Victor G odinho, membro do Serviço Sanitário e diretor da R evista M édica de São Paulo, junto a uma equipe de auxiliares de São Paulo e do M aranhão e alguns estudantes recém-formados em medicina do R io de Janeiro. E ntre janeiro e setembro

\footnotetext{
${ }^{20}$ Alfredo Augusto de $\mathrm{C}$ astro $\mathrm{M}$ edeiros, Considerações gerais sobrea varíola no B rasil ea conse qüenteintrodução desua profilaxia pela vacina animal, especialmenteem São P aulo, São Paulo, Trabal ho do Serviço Sanitário, I nstituto Vacinogênico, T i pografia do D iário O ficial, 1918, e R egina C andido G ualtieri, "Ciência e Serviço, O Instituto Butantan e a Saúde Pública (São Paulo: 1901-1927)", São Paulo, D issertação de M estrado, U niversidade de São Paulo, F aculdade de E ducação, 1994, pp. 73-76. Segundo a mesma autora, o soro antipeçonhento era também amplamente distribuído em diversos $E$ stados do B rasil e exportado para a $\mathrm{F}$ rança, a Alemanha e Cuba.

${ }^{21} \mathrm{M}$ arta de Almeida, "D a Cordilheira dos Andes...", op. cit.
} 
São Paulo na virada do século XX: um laboratório de saúde pública para o B rasil

de 1904, formou-se o "Serviço E xtraordinário de H igiene do E stado do M aranhão", que estabeleceu algumas instruções a serem cumpridas, pautadas em práticas desenvolvidas em São Paulo. 0 Instituto Butantan produziu grande quantidade de soro antipestoso naquele ano para atender à demanda, enviando $56 \%$ de sua produção para lá22. A missão, nas palavras de Victor G odinho, extrapolou a mera função de combate à peste, pois foi feito minucioso projeto de reestruturação dos órgãos sanitários daquele E stado, nos moldes do Serviço Sanitário de São Paulo23.

Além do reconhecimento das atividades - e do sucesso do empreendimento - por grande parte das autoridades médicas e governamentais de várias partes do Brasil, naquele mesmo ano Victor Godinho escreveu vários relatos de sua experiência no $M$ aranhão, publicados em formato de livro, enviado posteriormente para várias revistas médicas, numa franca propaganda da atuação do Serviço Sanitário de São Paulo²4. H avia a preocupação em divulgar a imagem civilizatória de São Paulo perante os outros E stados da federação, conciliada a uma idéia de irmandade entre duas regiões tão distintas. 0 elo de união para se pensar uma nação brasileira progressista davase, então, pelo sonho da construção de uma sólida rede sanitária com reconhecimento local e internacional.

Assim é que $E$ mílio R ibas, quando convidado por Patrick $M$ anson, em 1909, a participar de uma reunião na Society of Tropical M edicine and $H$ ygiene, em $L$ ondres, dissertou sobre a extinção da febre amarela não só em São Paulo como no R io de J aneiro, valorizando os procedimentos sanitários ocorridos no país ${ }^{25}$. Ainda naquele ano, por ocasião do $4^{\circ}$ Congresso $M$ édico $L$ atino-Americano, realizado na capital federal, novamente o Serviço Sanitário foi destaque em sua comunicação, na qual fez um balanço acerca de sua administração até ali ${ }^{26}$.

Ao relatar as diversas campanhas e ações voltadas para o combate da febre amarela, da varíola, da tuberculose e da febre tifóide, R ibas afirmou

\footnotetext{
${ }^{22}$ R egina C andido Gualtieri, Ciência eServiço..., op. cit., p. 73.

${ }^{23} \mathrm{M}$ arta de Almeida, República dos I nvisíveis..., op. cit., pp. 253-257.

${ }^{24}$ Vitor G odinho, A pesteno M aranhão, São Paulo, T ipografia do D iário O ficial, 1904.

${ }^{25} \mathrm{E}$ mílio R ibas, "T he extinction of yellow fever in the State of Sao Paulo (Brazil), and in the city of R io de J aneiro", Revista M édica de São Paulo, no 10, 1909, pp. 198-205.

${ }^{26}$ E mílio R ibas, "A H igiene no E stado de São Paulo", R evista M édica deSão Paulo, no14, 1909, pp. 277-282.
} 
que muitas doenças foram impedidas de entrar no país pela atuação do Serviço Sanitário de São Paulo e que o E stado "cooperava, mediante suas boas condições sanitárias, para o progresso do Brasil, o que significava estar junto com os povos cultos da América L atina" ${ }^{27}$, ou seja, dava-se muita importância à compreensão de que o bom estado sanitário de São Paulo fazia parte de um projeto maior de saneamento da nação.

É preciso não esquecer do cenário tenso das disputas políticas no início do século XX. Apesar do empenho paulista em seu esforço de divulgação e ação, pois não se tratava apenas de propaganda, havia competição entre Rio de J aneiro e São Paulo - nem sempre explícita- pela hegemonia de qual cidade poderia representar a moderna medicina da nação. Após as campanhas sanitárias empreendidas por 0 swaldo C ruz em plena capital federal e o enaltecimento, ainda em vida, que obteve de diversas partes do B rasil e do mundo, era muito difícil não respaldar o imaginário de um Brasil redimido pelas campanhas sanitárias de $M$ anguinhos. Até mesmo os médicos de São Paulo contribuíram para esta visão. No entanto, antes de tomar as medidas reformadoras da saúde pública no R io de J aneiro, O swaldo C ruz se correspondeu com E mílio Ribas e Ihe solicitou toda a legislação sanitária de São Paulo, com o intuito de utilizá-la no projeto de reestruturação dos serviços de saúde da U nião, a ser apresentado à Câmara dos $D$ eputados ${ }^{28}$. Infelizmente, este capítulo da história da saúde pública no Brasil ainda é muito pouco conhecido ou referenciado.

À guisa deconclusão

Ao consolidarem os serviços públicos de saúde e tendo como meta principal o saneamento de São Paulo, os articuladores das ações sanitárias ol havam não somente para os problemas locais, mas interagiam constantemente com outros centros científicos e sanitários e queriam, ao mesmo tempo, ser notad os e reconhecidos. 0 utros exemplos aqui poderiam ser lembrados, no sentido de reforçar esta idéia.

$H$ ouve um intenso intercâmbio entre os sanitaristas de São Paulo e do $R$ io de J aneiro, pelo menos no início do século XX, enquanto estratégia de

\footnotetext{
27 I bidem, p. 282.

${ }^{28}$ M arta de Almeida, República dos I nvisíveis..., op. cit., pp. 242-243.
} 
fortal ecimento de uma geração de profissionais ávidos em deixar sua marca nos novos rumos que o país tomava. 0 profícuo contato estabelecido entre médicos e cientistas paulistas e fluminenses, ainda que com disputas e hierarquizações, abre novas perspectivas de entendimento sobre a história da saúde pública do país, com ênfase para o papel desempenhado por São Paulo na institucionalização da microbiologia no Brasil.

As ações sanitárias ocorridas em São Paulo - campanhas, cursos médicos, publicações, pesquisas, divulgação e debates - tiveram amplitude nacional e internacional. D esta forma, concordamos com G il berto H ochman, ao propor, em seu estudo sobre o saneamento no Brasil, uma análise mais integrada, na qual se perceba que as mudanças sanitárias ocorridas em São Paulo tiveram repercussão, de al gum modo, nas reformas engendradas nos anos 20 para cuidar dos assuntos sanitários em âmbito federal ${ }^{29}$. Com base no estudo apontado neste artigo, podemos ampliar tal perspectiva e afirmar que as atuações voltadas para a saúde pública em São Paulo tiveram repercussão em outras localidades antes mesmo deste período. As medidas sanitárias de São Paulo serviram de base para a implementação de tantas outras, funcionando como uma espécie de "laboratório de saúde pública para o país" . O reconhecimento de seu papel na institucionalização dos primeiros serviços de saúde pública deve estar, portanto, articulado à história mais ampla do saneamento do Brasil.

\footnotetext{
${ }^{29}$ Gilberto H ochman, A era do saneamento. As bases da política de saúde pública no B rasil, São Paulo, H ucitec/AN POCS, 1998.
} 